\title{
Natural Dyeing of Cellulose and Protein Fibers with the Flower Extract of Spartium junceum L. Plant
}

\author{
Zorana Kovačević $^{1}{ }^{\oplus}$, Ana Sutlović ${ }^{1}$, , Ana Matin ${ }^{2}$ and Sandra Bischof ${ }^{1, *}$ \\ 1 Department of Textile Chemistry and Ecology, Faculty of Textile Technology, University of Zagreb, \\ 10000 Zagreb, Croatia; zorana.kovacevic@ttf.unizg.hr (Z.K.); ana.sutlovic@ttf.unizg.hr (A.S.) \\ 2 Department of Agricultural Technology, Storage and Transport, Faculty of Agriculture, University of Zagreb, \\ 10000 Zagreb, Croatia; amatin@agr.hr \\ * Correspondence: sbischof@ttf.unizg.hr; Tel.: +385-1-4877-351
}

Citation: Kovačević, Z.; Sutlović, A.; Matin, A.; Bischof, S. Natural Dyeing of Cellulose and Protein Fibers with the Flower Extract of Spartium junceum L. Plant. Materials 2021, 14 , 4091. https://doi.org/10.3390/ ma14154091

Academic Editor: Steve Eichhorn

Received: 29 June 2021

Accepted: 19 July 2021

Published: 22 July 2021

Publisher's Note: MDPI stays neutral with regard to jurisdictional claims in published maps and institutional affiliations.

Copyright: (C) 2021 by the authors. Licensee MDPI, Basel, Switzerland. This article is an open access article distributed under the terms and conditions of the Creative Commons Attribution (CC BY) license (https:/ / creativecommons.org/licenses/by/ $4.0 /)$.

\begin{abstract}
In this study, the natural dye was extracted from Spartium junceum L. (SJL) flowers and applied on cellulose (cotton) and protein (wool) fabric. Fabrics were pre-mordant with alum prior to the dyeing process. Considering the global requirements on zero waste and green policy, the dyeing process was intended to be as much as possible environmentally friendly but still effective. Therefore, mordant concentration was optimized due to the reduction of the negative impact. The efficiency of the dyeing process was investigated by examination of fabrics' color characteristics and colorfastness to washing properties. In this paper, we have proved that the extracted dye from Spartium junceum L. is an acidic dye (mordant dye) which is more applicable for the treatment of wool fabrics. In this paper, it was proved that phytochemicals responsible for coloring are part of the flavonoids group. The UV absorption spectra of extracted dye show 4 bands in the region of $\lambda_{\max } 224,268,308$ and $346 \mathrm{~nm}$ which are ascribed to bands characteristic for flavonoids. Wool fabric pre-mordant with $3 \%$ alum and dyed shows great chromatic $\left(C^{*}\right)$ properties where $C^{*}$ value is in a range from 47.76 for unwashed samples to 47.50 for samples after 5 washing cycles and color hue $\left(\mathrm{h}^{\circ}\right)$ is in a range 82.13 for unwashed samples to 81.52 for samples after 5 washing cycles. The best result regarding the colorfastness properties is shown by the wool sample treated with $3 \%$ alum after 5 washing cycles (total difference in color (Delta $\left.E^{*}\right)=0.87$ ). These results confirm that metal (Al) from alum mordant make strong chemical bonds with wool substrate and dye since Delta $E^{*}$ values decrease in comparison to Delta $E^{*}$ values of the cotton samples treated the same way. The results revealed it is possible to reduce the concentration of mordant up to $3 \%$ and obtain satisfactory results regarding the colorfastness. Nevertheless, future research will go in the direction of replacing synthetic mordant with a more environmentally friendly one.
\end{abstract}

Keywords: Spartium junceum L.; natural dye; mordant dye; cellulose fibers; protein fibers; wool dyeing; flavonoids; colorfastness to washing

\section{Introduction}

Since an interdisciplinary approach is desirable within the science community, this research comprises several specific objectives, which seeks to find new solutions for a better understanding of the investigated topic. The wide availability of indigenous Mediterranean plants directs research towards sustainable development and circular economy. Furthermore, utilization of widely available biomass for natural dye production will be applied in the dyeing of protein and cellulosic textile materials with emphasis on the aspects of textile care.

Spartium junceum L. (SJL) or Spanish broom is a Mediterranean plant, which has been used as a textile raw material since ancient times. Its greatest use was in fiber production but it was also well known for its flowers which are blooming between May and July [1]. It is interesting that the SJL plant as a raw material resource was mostly 
used in the period of poverty between the great wars but afterward was abandoned. Although, it is native to southern Europe and the Mediterranean area, including North Africa, Turkey and the Middle East it becomes an aggressive invader in many tropical, subtropical and temperate regions of the world. For example, in the USA, the Canary Islands, the Azores, Argentina, Bolivia, Peru, Uruguay, South Africa and the Dominican Republic SJL is considered an invasive, noxious weed [2,3]. Nowadays, SJL is applied again as a renewable raw material which could have numerous possibilities of usage for the production of fibers, yarns, fabrics, ropes, baskets, composite materials reinforced with SJL fibers [1], decorative and artistic items, painting canvas, oils, perfumes, and natural dyes by following the concept of circular economy [4] and zero waste model. Aqueous extracts prepared from the flowers were used as herbal medicine in the treatment of gastric ulcers in Turkish folk medicine, against herpes simplex virus type 1 in recent times [5] and in yellow dye production [6,7]. Regardless of the fact that natural dyes were successfully used for fabric dyeing in ancient times, the discovery of synthetic dyes in the 19th century significantly improved and facilitated the dyeing process by achieving cheaper dyes. Due to increased awareness of the environmental and health hazards and cognition of toxicity and carcinogenicity of synthetic dyes products, most commercial dyers have started to search up again for renewable and sustainable natural dyes derived from the plant, animal and mineral sources in accordance with EU regulations. REACH (EC No. 1907/2006) and Ecolabel (EC No. 66/2010) regulations provide restrictions on the usage of dyes that are considered dangerous to human health [8,9]. EU Directives must be implemented by the EU member states in their national legislation and monitored by the national authorities.

Natural dyes show two main advantages compared to synthetic dyes: synthesis processes within natural materials performed by nature without environmental pollution and biodegradability of natural materials, thus not affecting hazardous effluent upon degradation in the environment [10]. The limitation of natural dyes upon the synthetic one is their reproduction of color since the quality of natural dyes depends on the climate, plant genus, region, etc. [10,11]. The dyeing of textile materials is influenced by dyeing parameters such as fiber structure, temperature, time and $\mathrm{pH}$ of the dye bath and dye molecule characteristics. The efficiency of dyes on textile materials depends on the stability of the dyes / fiber complex. Cellulose fibers show poor affinity and substantivity according to natural dyes causing difficulties in the dyeing process. Protein fibers, on the contrary, show better affinity to natural dyes since they have ionic groups in their structure and get stronger bonds with natural dyes possessing ionic groups in dye structure [12,13].

Natural dyes can be classified based on their chemical structure, origin, method of application and color. Based on the chemical structure they belong to classes of indigoids, anthraquinonoids, ketones, imines, betalains, anthocyanidins, flavonoids, carotenoids or chlorophylls. Based on their method of application they can be classified as mordant dyes, direct dyes, vat dyes, acid dyes, basic dyes and disperse dyes [14,15]. According to the literature [16] flavonoids (water soluble polyphenols) give yellow color to SJL flowers. Chemically flavonoids are divided into flavones, flavonols, isoflavones, flavanones, chalcones and arones. The SJL plant's dried flowers contain luteolin and quercetin dyes. Luteolin is part of the flavones subclass, which are UV absorbing flavonoids, while quercetin is part of the flavonols subclass. Today, in addition to aqueous extraction, modern methods are used for the extraction of pigments from plant sources, e.g., microwaves [17], ultrasound [18], supercritical $\mathrm{CO}_{2}$ [19]. These methods are used for qualitative analysis, however, in the application of these components in the field of microbiology and green synthesis, aqueous extraction is still preferred. Quercetin and luteolin belong to the mordant dyes class [20], which is equally suitable for both vegetable and animal fibers [21]. In most ways, mordant dyes show soft, pastel and lustrous shades soothing to the human eye but one of their main drawbacks is little affinity for textile substrates causing poor colorfastness to washing, rubbing, sweat and sunlight [22]. Mordant dyes are acid dyes and have an anionic character, therefore requiring mordants in their formulations to fix dyes on fibers and improve the quality and fabric's color brightness [20-23]. Mordants can 
be natural (tannic acid, citric acid, clay, bark extracts, etc.) or synthetic (various metallic salts, such as alum, stannous chloride, copper sulfate, ferrous sulfate, etc.) [23]. Metallic mordants are usually used for fabrics pretreatment before the dyeing process. Different metal mordants impact various coloration effects with the same natural dye. The final color experience does not depend only on a dye but is also affected by the type and concentration of mordant. In this paper, we have used alum, metallic salt of potassium aluminum sulfate

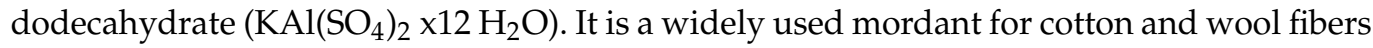
which show the lowest negative ecological impact among other metallic mordants [24]. It is recommended to add approx. $12 \%$ of alum on the weight of the fabric [25] but in this paper, we have investigated the color enhancement of pre-mordant fabrics with a much lower amount of alum (3 to $5 \%$ ) and color changes of such fabrics after the washing process. Studies about SJL dye's colorfastness to washing are very rare in the literature. In this paper, the possibility of the usage of the aqueous extract from the SJL flowers as a natural dye for the cellulose and protein fabrics was evaluated. The novelty of this work is in the direct contribution towards the principles of a circular economy where each part of the plant is successfully utilized for the production of fibers and/or technical textiles, so as for the extraction of natural dyes.

\section{Experimental}

\subsection{Materials}

Two different textile fabrics were used in the experiment: cotton and wool fabrics with characteristic parameters presented in Table 1.

Table 1. Technical characteristic parameters of used fabrics.

\begin{tabular}{|c|c|c|c|c|c|c|}
\hline \multirow{2}{*}{ Label } & \multirow{2}{*}{ Composition } & \multirow{2}{*}{ Producer } & \multirow{2}{*}{ Weave } & \multicolumn{2}{|c|}{ Density $\left(\mathrm{cm}^{-1}\right)$} & \multirow{2}{*}{ Weight $\left(\mathrm{g} / \mathrm{m}^{2}\right)$} \\
\hline & & & & Warp & Weft & \\
\hline $\mathrm{C}$ & $100 \%$ Cotton & Čateks d.o.o., Čakovec, Croatia & Plain & 26 & 25 & 191.45 \\
\hline W & 100\% Wool & Tekstilpromet d.d., Zagreb, Croatia & Plain & 22 & 22 & 118.16 \\
\hline
\end{tabular}

Spartium junceum L. flowers were picked near the town of Šibenik (Figure 1).

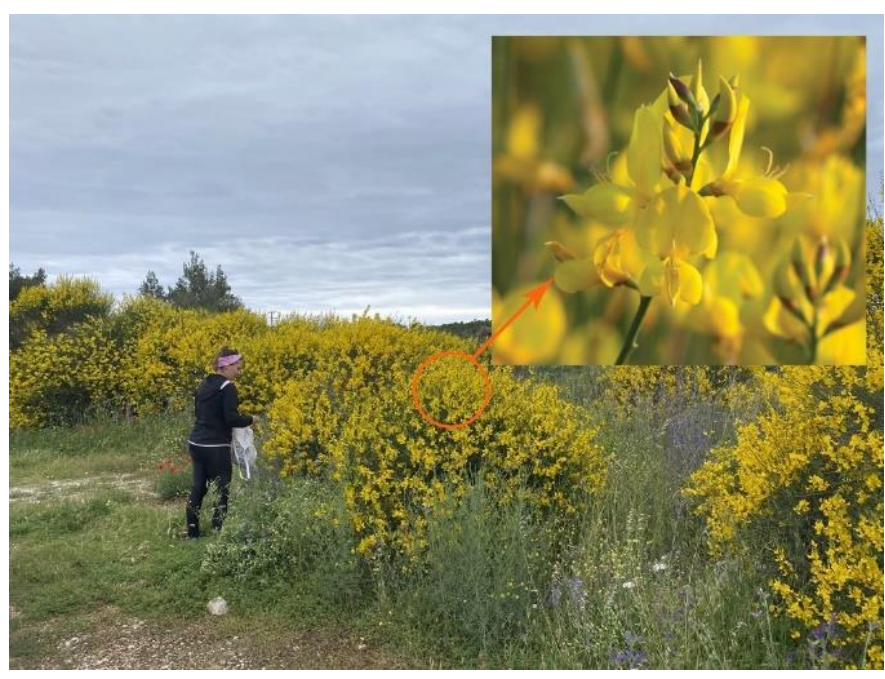

Figure 1. Collecting of Spartium junceum L. flowers in May 2021.

\subsection{Natural Dye Extraction}

Spartium junceum L. flowers were used as an herbal source for biological pigment extraction. The dye was extracted by boiling flowers in distilled water at material-liquor ratio (MLR) 1:2.7, at $100{ }^{\circ} \mathrm{C}$ for $1 \mathrm{~h}$. After the first extraction process, the dye solution 
was filtered and evaporated water was adjusted with distilled water to a volume of $3 \mathrm{~L}$. Extraction process was repeated twice by using residual flowers after the first extraction.

\subsubsection{Determination of $\mathrm{pH}$ Values}

The $\mathrm{pH}$ values of dye solutions were measured by $\mathrm{pH}$ meter MA 5736, Metrel (Iskra), Slovenia with the glass-electrode method. Prior to the measurement $\mathrm{pH}$ meter was calibrated in the solution of $\mathrm{pH} 3, \mathrm{pH} 5$ and $\mathrm{pH} 7$ buffers.

\subsubsection{Determination of the Crude Dye Yield}

The mass of the crude dye was determined by the evaporation method. To do this, $100 \mathrm{~mL}$ of the extracted and filtered dye solution was placed in the Petri dish and heated in the oven at $105 \pm 2{ }^{\circ} \mathrm{C}$ for $24 \mathrm{~h}$. Crude solid dry material weight after evaporation was calculated on the volume of $3 \mathrm{~L}$. The solid and dried dye was weighed, and the percentage of crude dye was calculated using Equation (1) in relation to the original weight of plant material used for extraction.

$$
\mathrm{Wcd}=(\mathrm{Wae}) / \mathrm{Wbe}) * 100,
$$

where Wcd-percentage yield of crude dye (\%); Wae-crude solid dry material weight after evaporation (g); Wbe-dry material weight before extraction (g).

\subsubsection{FT-IR Spectroscopy}

Fourier transform infrared (FT-IR) spectra were obtained with a Perkin Elmer Spectrum 100 FT-IR spectrometer using ATR (attenuated total reflection) method. The analyses were carried out at room temperature and ambient humidity. All spectra were registered from $4000 \mathrm{~cm}^{-1}$ to $380 \mathrm{~cm}^{-1}$, with a resolution of $4 \mathrm{~cm}^{-1}$. The background was collected at the beginning of the measurement. Each spectrum was collected from an average of 4 scans.

\subsubsection{UV-VIS Spectrophotometry}

The absorption spectra of the dye solutions were measured using a UV-Vis spectrophotometer, UV-2600, Shimadzu Europe, Germany at a wavelength from 200 to $800 \mathrm{~nm}$.

\subsection{Fabric Treatment}

\subsubsection{Pre-Mordanting Process}

Pre-mordanting of cotton and wool fabrics was applied by using potassium aluminum sulfate dodecahydrate $\mathrm{KAl}\left(\mathrm{SO}_{4}\right)_{2} \times 12 \mathrm{H}_{2} \mathrm{O}$. MLR ratio was $1: 40$, at $50{ }^{\circ} \mathrm{C}$ for $30 \mathrm{~min}$ with mordant concentrations of $3 \%$ and $5 \%$ on the weight of the fabric. After mordanting, fabrics were air dried.

\subsubsection{Dyeing Process}

Cotton and wool fabrics were dyed in water extract of Spartium junceum L. flowers by exhaustion method with MLR 1:40, at $90{ }^{\circ} \mathrm{C}$ for $60 \mathrm{~min}$. Dyeing was performed with and without mordanting process using dye solution after the first extraction. Afterward, the fabrics were thoroughly washed in cold water, followed by hot soaping with Kemopon 30, CHT Bezema, Switzerland and cold rinsing.

\subsubsection{Washing Process}

The washing process was carried out at MLR 1:20, at $60{ }^{\circ} \mathrm{C}$ for $30 \mathrm{~min}$, through 5 cycles using the apparatus Turbomat P4502, Mathis, Switzerland. The washing bath was made with $2.5 \mathrm{~g} / \mathrm{L}$ ECE-2 colorfastness test detergent, without using phosphate, ISO 105-C08/C09. Washed fabrics were dried between the washing cycles. Colorfastness to washing was tested by colorimetric evaluations. 


\subsubsection{Color Measurement}

The color coordinates of dyes were determined on spectrophotometer Datacolor 850 , Switzerland under illuminant $\mathrm{D} 65$, using $\mathrm{d} / 10^{\circ}$ geometry. The coordinates used to determine color values are " $\mathrm{L}^{*}$ " for lightness, " $\mathrm{a}^{* \prime}$ for redness (positive value) and greenness (negative value), " $b$ " " for yellowness (positive value) and blueness (negative value), " $\mathrm{C}$ "” for chroma and " $\mathrm{h}$ " for hue angle in the range of $0^{\circ}$ to $360^{\circ}$.

The changes in coloration of unwashed and washed samples were characterized by the difference in lightness " $\mathrm{dL}^{*}$ ", hue " $\mathrm{dH}^{*}$ ", chroma " $\mathrm{dC}^{*}$ " and the total difference in color “Delta E*".

Delta $\mathrm{E}\left(\Delta \mathrm{E}^{*}\right)$ was calculated by the following Equation (2):

$$
\Delta \mathrm{E}^{*}=\left[\left(\Delta \mathrm{L}^{*}\right)^{2}+\left(\Delta \mathrm{a}^{*}\right)^{2}+\left(\Delta \mathrm{b}^{*}\right)^{2}\right]^{1 / 2},
$$

where $\Delta \mathrm{L}^{*}=\mathrm{L}^{*}$ washed- $\mathrm{L}^{*}$ unwashed; $\Delta \mathrm{a}^{*}=\mathrm{a}^{*}$ washed-a* unwashed; $\Delta \mathrm{b}^{*}=\mathrm{b}^{*}$ washed$b^{*}$ unwashed.

Color strength (K/S) was calculated by the Kubelka-Munk Equation (3):

$$
K / S=(1-R)^{2} / 2 R,
$$

where $\mathrm{K}$ is the absorption coefficient, $\mathrm{S}$ is the scattering coefficient and $\mathrm{R}$ is the remission value (reflectance of the dyed fabric) at $\Lambda_{\max }$.

The color coordinates were measured before and after the 1st, 3rd and 5th washing cycle.

\section{Results and Discussion}

\subsection{Sample Labeling}

Samples labels were defined according to material composition, dye extraction, premordanting and washing process:

$$
\text { C/W_E_Me_Wx, }
$$

where $\mathrm{C} / \mathrm{W}$ stands for fiber type ( $\mathrm{C}$ for cotton and $\mathrm{W}$ for wool fabric), E stands for the extraction process of dye solutions (1E for 1st extraction, 2E for 2nd extraction and 3E for 3rd extraction), Me is mordant concentration (from 0 to $5 \%$ on the weight of the fabric) and $\mathrm{Wx}$ is number of washing cycles (from 0 to 5 cycles).

\subsection{Analysis of Dye Extract}

\subsection{1. $\mathrm{pH}$ Values of Aqueous Dye Solutions}

All the investigated solutions show $\mathrm{pH}$ values around 5 indicating the acidic range. 1st extraction (1E) shows $\mathrm{pH} 5.4$ at $21.3^{\circ} \mathrm{C}$, 2nd extraction (2E) shows $\mathrm{pH} 5.5$ at $20.6{ }^{\circ} \mathrm{C}$ and 3rd extraction (3E) shows pH 5.6 at $22.9^{\circ} \mathrm{C}$. Acidic dye solutions are most often anionic in nature and are suitable for the dyeing of protein fibers and polyamide as well $[26,27]$.

\subsubsection{Crude Dye Yield}

Crude dye yield is an indicator of the total extracted pigments from the plant source. It significantly depends on the characteristics of the plant (climate, harvesting time, etc.) and on the extraction process parameters $(\mathrm{pH}$, temperature, time) as well. The highest amount of extracted pigment which can be objectively assessed from the Table 2 and visually from Figure 2 is obtained after 1st extraction.

Table 2. Crude dye yield in the investigated dye solutions.

\begin{tabular}{ccc}
\hline Dye Solutions & Mass of the Crude Dye (g) & Crude Dye Yield (\%) \\
\hline $1 \mathrm{E}$ & 52.8 & 4.8 \\
$2 \mathrm{E}$ & 25.98 & 2.4 \\
$3 \mathrm{E}$ & 12.48 & 1.1 \\
\hline
\end{tabular}




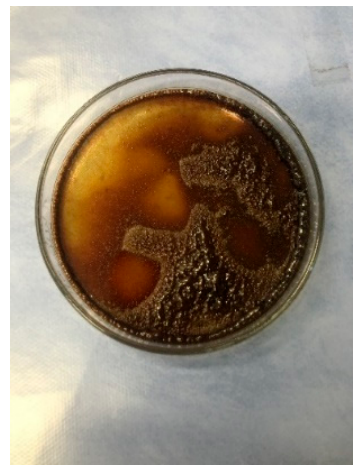

(a)

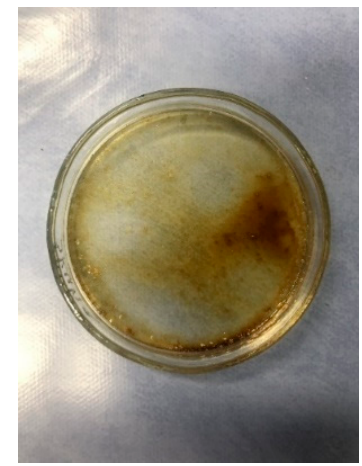

(b)

Figure 2. Evaporated residue of (a) 1st extraction dye solution (1E) and (b) 3rd extraction dye solution (3E).

Natural dyes of plant origin, most commonly from the flavonoid group, have been shown to have good solubility in acidic media since glycosides are resistant to acid hydrolysis resulting in better pigment extraction $[6,12,16,28,29]$. Alkaline media is used in the extraction of compounds, which contain phenolic groups [29,30]. Therefore, flavonoid derivatives are most often detected in the acidic extract. In this paper, a relatively small amount of crude dye yield was obtained after 1st acidic extraction (4.8\%), which is further reduced by $50 \%$ in each subsequent dyeing process. The results after crude dye yield calculation indicate the unprofitability of using $2 \mathrm{E}$ and $3 \mathrm{E}$ dye solution, therefore multiple extractions of the collected plant are not recommended for further research. As can be seen from Figure 2, 3E dye solution is inadequate so 1E dye solution was applied in this experiment. This was also confirmed by VIS spectrophotometric analysis of the extracts.

\subsubsection{UV-VIS Spectrophotometry}

The UV absorption spectra of Spartium junceum L. dye solutions after 1 cycle of extraction (1E) are shown in Figure 3. It shows 4 bands in the region of $\lambda_{\max } 224,268$, 308 and $346 \mathrm{~nm}$ which are ascribed to benzoyl and cinnamoyl bands characteristic for flavonoids [31]. Flavonoids are comprised of two benzene rings linked via a heterocyclic pyrane ring visible as a band at $224 \mathrm{~nm}$ which correlates well with the literature [12,32]. In the paper published by Amat, A. et al., the UV absorbance band of luteolin was measured in acidic media and found to be $348 \mathrm{~nm}$ which is in line with our measurements [33]. The peak at $268 \mathrm{~nm}$ is characteristic of flavonols, the subclass of flavonoids whose representative is quercetin [34].

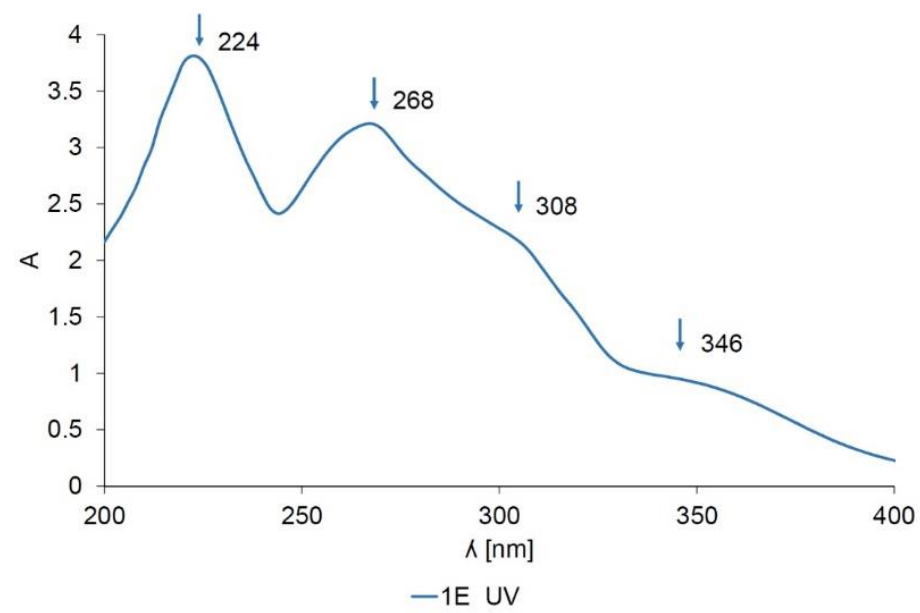

Figure 3. The UV absorption spectra of dye solution 1E. 
The absorbance spectra of Spartium junceum L. dye solutions after 3 cycles of extraction are shown in Figure 4. As can be seen, the dye solution from the first extraction shows the highest absorption intensity at $400 \mathrm{~nm}$ wavelength in the visible area, which proved the presence of the highest amount of extracted pigments. According to the literature [16], Spartium junceum L. flowers contain luteolin and quercetin dyes responsible for its yellow color. Flavonoids like luteolin and quercetin are expected to have the highest absorbance in the yellow area (from 390 to $450 \mathrm{~nm}$ ) [12].

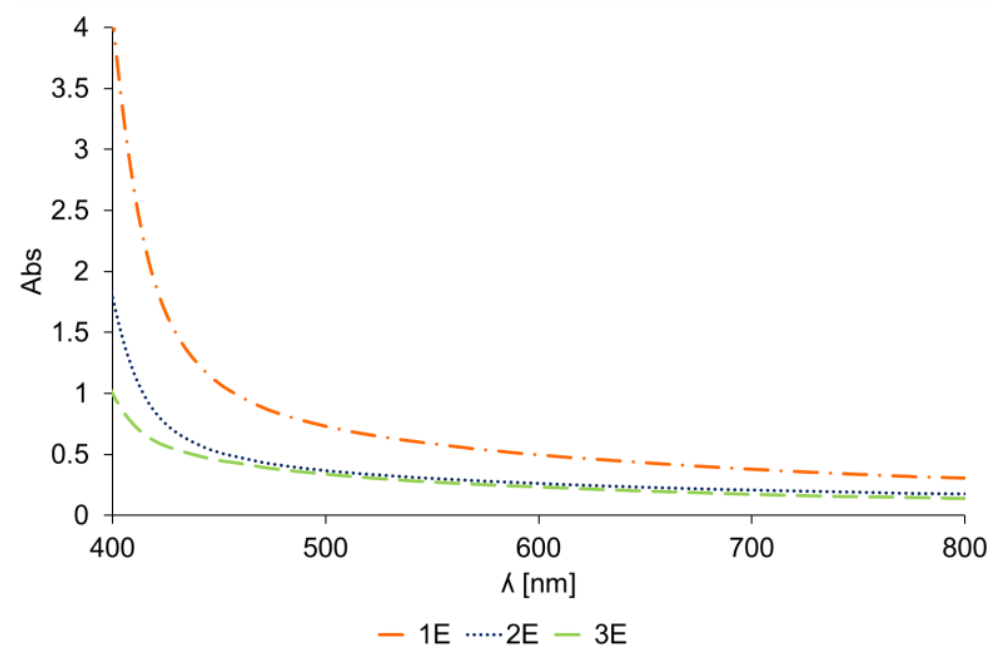

Figure 4. The VIS absorption spectra of 1st extraction (1E), 2nd extraction (2E) and 3rd extraction (3E).

\subsubsection{FT-IR Spectra of Crude Dye}

The color of SJL flowers is directly connected to the presence of flavonoids, which are mainly present in yellow colored parts of plants $[15,16]$. FTIR technique was applied for possible differentiation of flavonoids subclasses presented in examined crude dye [12,28].

FTIR spectra of crude dye after the first extraction are presented in Figure 5.

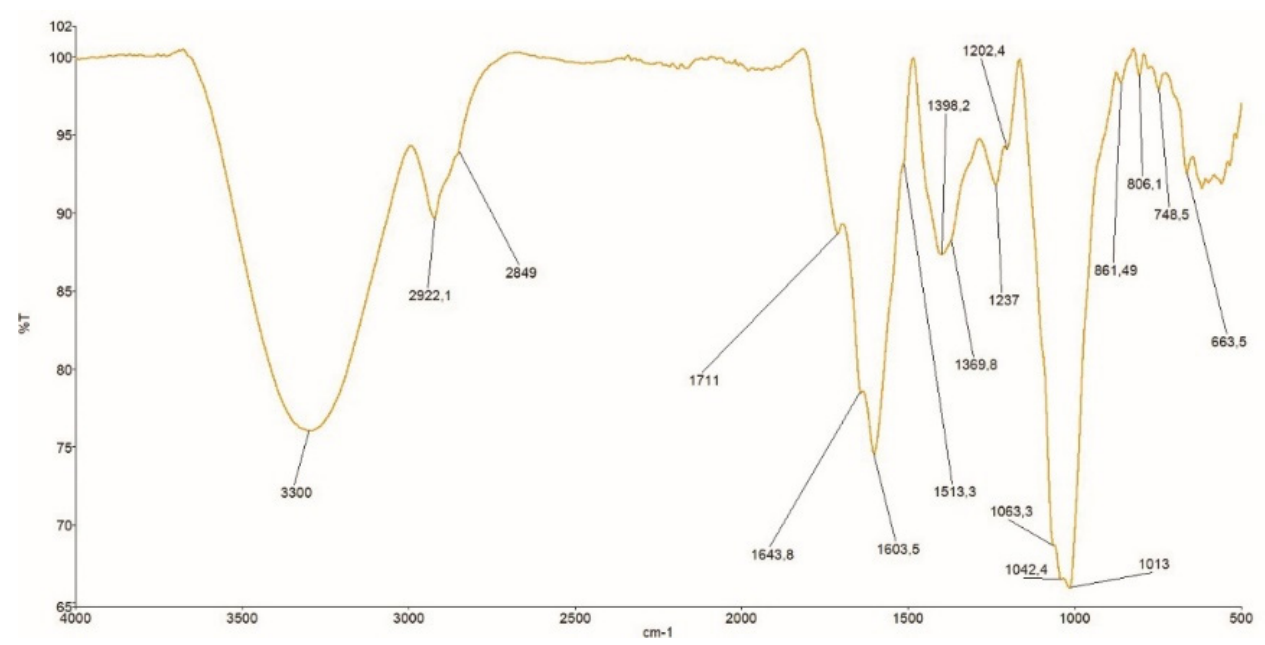

Figure 5. The transmission FTIR spectra of the first extraction (1E) crude dye.

This spectrum can be divided into six regions:

1. 4000-2500: associated with the stretching vibrations of $\mathrm{OH}$ functional group of phenols $\left(3300 \mathrm{~cm}^{-1}\right)$ and aromatic $\mathrm{CH}$ and $\mathrm{CH}_{2}$ stretching vibrations of alkenes (2849 and $2922 \mathrm{~cm}^{-1}$ ) [35];

2. 2499-1800: this region didn't show any applicable spectral information; 
3. 1799-1630: assigned to double bond stretching vibrations (band at $1711 \mathrm{~cm}^{-1}$ corresponding to $\mathrm{C}=\mathrm{O}$ stretch of ketone, and band at $1643 \mathrm{~cm}^{-1}$ corresponding to carbonyl group characteristic for flavones, i.e., for luteolin [36,37];

4. 1629-1400: assigned to $C=C$ stretching of the aromatic ring $\left(1603 \mathrm{~cm}^{-1}\right.$ and $\left.1513 \mathrm{~cm}^{-1}\right)$;

5. 1399-1200: associated with C-OH deformations vibrations of phenols $\left(1398 \mathrm{~cm}^{-1}\right.$ and $\left.1369 \mathrm{~cm}^{-1}\right)$ and $\mathrm{C}-\mathrm{O}$ stretching vibrations of aromatic ethers in phenols $\left(1237 \mathrm{~cm}^{-1}\right)$ and $\mathrm{C}-\mathrm{O}$ stretching band due to pyranose structure $\left(1202 \mathrm{~cm}^{-1}\right)$ [38];

6. 1199-700: assigned to $\mathrm{C}-\mathrm{O}$ stretching vibrations (1063 and $1042 \mathrm{~cm}^{-1)}, \mathrm{C}-\mathrm{OH}$ stretching vibrations characteristic for flavanols, i.e., for quercetin $\left(1013 \mathrm{~cm}^{-1)}\right.$ and out of plane $\mathrm{CH}$ deformation vibrations of the functional groups mainly from carbohydrates (region from 900 to $700 \mathrm{~cm}^{-1)}[12,28,39,40]$.

The spectral area from 1799 and $700 \mathrm{~cm}^{-1}$ is called the "fingerprint region" and is notable for the large number of infrared bands and is very important to characterize the sample's chemical structure.

\subsection{Analysis of Fabrics after Pre-Mordanting, Dyeing and Washing}

\subsubsection{Color Measurement}

K/S values of cotton and wool fabrics are presented in Figures 6 and 7. Figure 6 shows the effect of different mordant concentrations on dyed and undyed cotton fabrics. It is also visible that different aluminum mordant concentration does not significantly affect the K/S value. Vankar, P.S. et al. [31] stressed out that alkaline $\mathrm{pH}$ allows the strongest affinity of $\mathrm{Al}^{3+}$ metal to natural dye than acidic $\mathrm{pH}$. Consequently, such low color strength is due to poor metal bonding with cellulose substrate and natural dye. Furthermore, Glogar, M.I. et al. presented in their paper [41] how the sample surface affects color strength as well. Smooth fabrics like cotton produce lower K/S compared to fabrics with a rougher surface (e.g., wool).

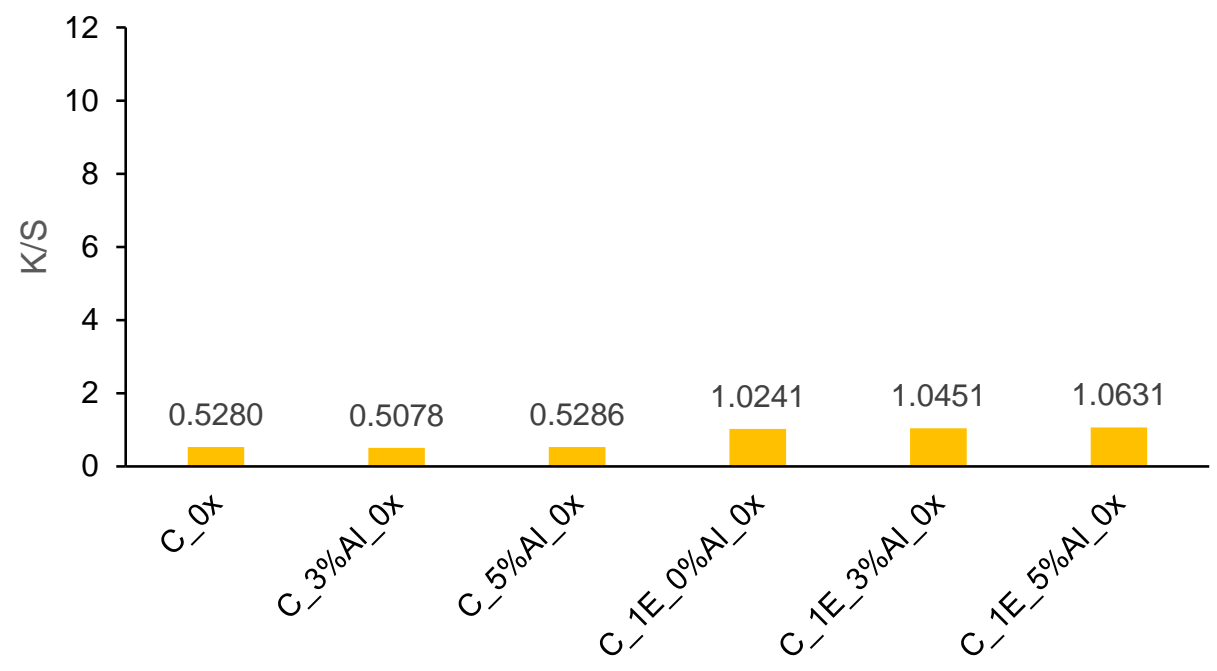

Figure 6. K/S values of cotton samples which are untreated (C_0x), treated only with mordants (C_3\%Al_0x and C_5\%Al_0x) or dyed with (C_1E_3\%Al_0x and C_1E_5\%Al_0x) and without mordants (C_1E_0\%Al_0x).

Figure 7 shows the effect of different mordant concentrations on dyed and undyed wool fabrics. The undyed wool substrate shows slightly yellow color. It was observed that by increasing the alum concentration up to $3 \%$ and $5 \%$ on undyed wool substrates, the color strength was decreased by $7.91 \%$ and $15.73 \%$ indicating poor bonding between wool and metal ions. Metal ions from alum mordant cause linking between dye and wool substrate by forming covalent bonding between functional groups of the dye molecule $(\mathrm{OH}, \mathrm{C}=\mathrm{O})$ and protein fiber $\left(\mathrm{NH}_{2}, \mathrm{COOH}\right)$. Dyed wool fabrics treated with $3 \%$ and 
$5 \%$ alum mordant show an increase in $\mathrm{K} / \mathrm{S}$ value compared to dyed wool fabric without mordant for $34.87 \%$ and $63.21 \%$, respectively.

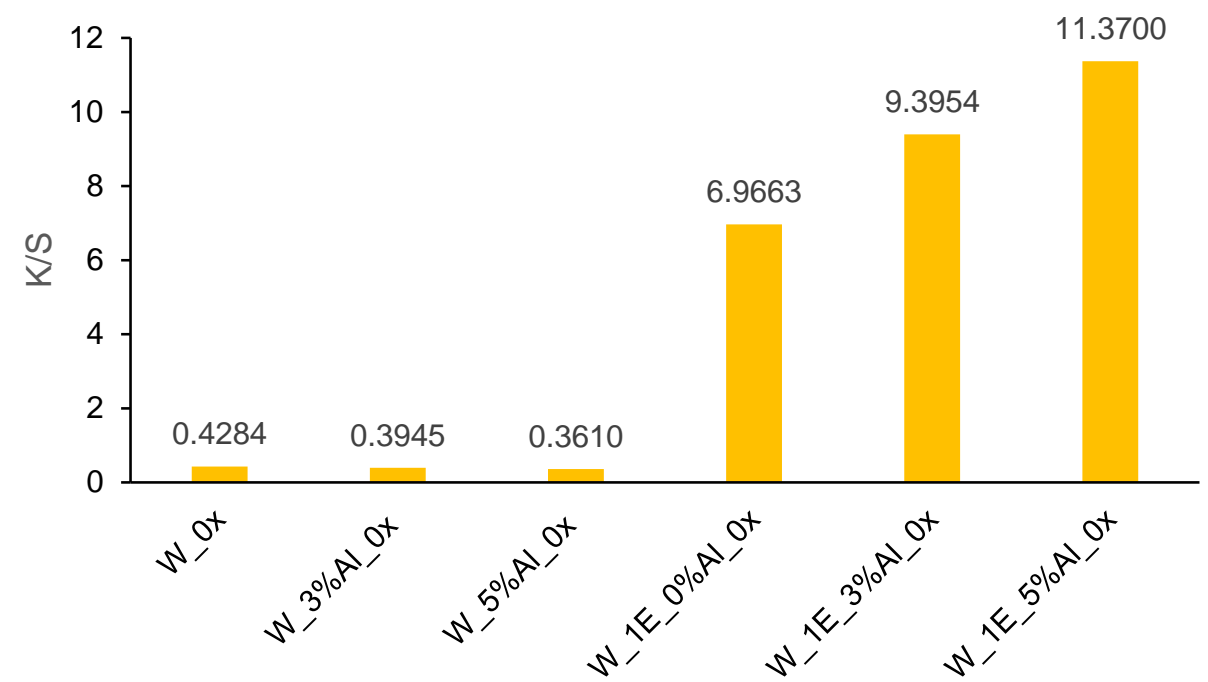

Figure 7. K/S values of wool samples which are untreated (W_0x), treated only with mordants (W_3\%Al_0x and W_5\%Al_0x) or dyed with (W_1E_3\%Al_0x and W_1E_5\%Al_0x) and without mordants (W_1E_0\%Al_0x).

A huge difference between cotton and wool fabrics regarding the color strength is related to the charge of the dye and fabric. In this research, the acidic dye was extracted from the Spartium junceum L. flowers which has an anionic character and negative charge. Cotton fabric has a negative charge as well. Since the same charges repel each other, it was apparent that cotton fabric with current conditions would not show sufficient color strength compared to the wool fabric which is positively charged and therefore much more prone to fiber/mordant/dye crosslinking [42-45].

Table 3 presents that pre-mordant and undyed cotton samples show a minor decrease in lightness, chroma and hue for $0.19 \%, 11.47 \%$ and $1.19 \%$, respectively for sample premordant with $3 \%$ alum.

Table 3. Color coordinates of cotton samples dyed with SJL aqueous extract with and without mordants before washing.

\begin{tabular}{cccccc}
\hline Samples & $\mathbf{L}^{*}$ & $\mathbf{a}^{*}$ & $\mathbf{b}^{*}$ & $\mathbf{C}^{*}$ & $\mathbf{h}$ \\
\hline C_0x & 97.27 & 3.33 & -11.20 & 11.68 & 286.54 \\
C_3\%Al_0x & 97.09 & 2.35 & -10.07 & 10.34 & 283.14 \\
C_5\%Al_0x & 96.82 & 2.34 & -9.93 & 10.20 & 283.27 \\
C_1E_0\%A1_0x & 90.09 & -1.73 & 17.52 & 17.60 & 95.65 \\
C_1E_3\%Al_0x & 90.02 & -2.10 & 20.45 & 20.55 & 95.86 \\
C_1E_5\%A1_0x & 90.01 & -2.05 & 21.30 & 21.39 & 95.49 \\
\hline
\end{tabular}

They also show a decrease in lightness, chroma and hue for $0.46 \%, 12.67 \%$ and $1.14 \%$, respectively for sample pre-mordant with $5 \%$ alum, both regarding the reference samples C_0x. Subjective visual assessment of dyed cotton samples matches the objective measurement and gives light yellow color. These samples show no significant differences in hue $\left(h^{\circ}\right.$ is in the range from 95.49 to 95.86$)$ and lightness values ( $L^{*}$ is in the range from 90.01 to 90.09 ). Dyed cotton sample without previous mordanting shows the highest lightness value $\left(L^{*}=90.09\right)$ and the lowest chroma value $\left(C^{*}=17.60\right)$ within series of dyed samples. The increase in chroma value is noticeable for dyed cotton samples, which are pre-mordant with $3 \%$ and $5 \%$ alum for $16.76 \%$ and $21.53 \%$, respectively, regarding the dyed cotton sample without previous mordanting (C_1E_0\%Al_0x). According to the paper published by Repon, M.R. et al. pre-mordanting of cotton fabric with $5 \%$ alum shows 
slightly positive impact on color saturation of dyed cotton fabric but negative impact on the environment since $\mathrm{Al}^{3+}$ metal from alum mordant shows lower exhaustion on material surface due to its lower coordination number [11].

Table 4 presents that pre-mordant and undyed wool samples show a minor decrease in lightness and chroma for $0.36 \%$ and $7.85 \%$, respectively, while a minor increase in hue for $1.17 \%$, for sample pre-mordant with $3 \%$ alum regarding the reference sample $\mathrm{W} \_0 \mathrm{x}$ occurs.

Table 4. Color coordinates of wool samples dyed with SJL aqueous extract with and without mordants before washing.

\begin{tabular}{cccccc}
\hline Samples & $\mathbf{L}^{*}$ & $\mathbf{a}^{*}$ & $\mathbf{b}^{*}$ & $\mathbf{C}^{*}$ & $\mathbf{h}$ \\
\hline W_0x & 90.45 & -1.04 & 12.83 & 12.87 & 94.62 \\
W_3\%Al_0x & 90.12 & -1.18 & 11.80 & 11.86 & 95.73 \\
W_5\%Al_0x & 91.24 & -1.18 & 11.68 & 11.74 & 95.76 \\
W_1E_0\%Al_0x & 71.70 & 5.01 & 38.42 & 38.74 & 82.56 \\
W_1E_3\%Al_0x & 70.91 & 6.54 & 47.31 & 47.76 & 82.13 \\
W_1E_5\%Al_0x & 69.96 & 7.98 & 51.02 & 51.64 & 81.11 \\
\hline
\end{tabular}

Wool sample pre-mordant with $5 \%$ alum shows an increase in lightness and hue for $0.87 \%$ and $1.20 \%$, respectively and a decrease in chroma for $8.78 \%$, regarding the reference sample W_0x. Dyed wool samples show higher intensity in coloration than cotton samples which is assessed by subjective visual method and confirmed objectively by color coordinate measurements. Comparing cotton and wool dyed samples noticeable decrease in lightness ( $\mathrm{L}^{*}$ was approx. 90 for cotton and 70 for wool samples) and hue $\left(\mathrm{h}^{\circ}\right.$ was approx. 95 for cotton and 82 for wool samples) occurs while at the same time increase in chroma values ( $C^{*}$ was approx. 20 for cotton and 46 for wool samples) happens. Haji, A. et al. have shown in their research paper mechanism of attachment of quercetin to wool structure assisted with the addition of alum mordant. One molecule of mordant binds the protein fiber while at the same time holding one or two molecules of dye with it, causing an increase of the affinity between wool fiber and dye and its color yield as well [46].

Similar to cotton, dyed wool sample without previous mordanting shows the highest lightness value $\left(\mathrm{L}^{*}=71.70\right)$ and the lowest chroma value $\left(\mathrm{C}^{*}=38.74\right)$ within series of dyed samples. Samples which are dyed and pre-mordant with $5 \%$ alum show lowest lightness value $\left(\mathrm{L}^{*}=69.96\right)$ and highest chroma $\left(\mathrm{C}^{*}=51.64\right)$.

The impact of multiple washing cycles on the color fastness of cotton and wool dyed fabrics was monitored through an objective color measurement technique. Colorfastness to washing is an important factor since most dyed fabrics are frequently washed after their usage. Results were presented in Tables 5-18.

Table 5. Change in color coordinates of the cotton sample without mordants after 1st, 3rd and 5th washing cycle (compared with C_0x).

\begin{tabular}{ccccc}
\hline Samples & $\mathbf{d L}^{*}$ & $\mathbf{d C}^{*}$ & $\mathbf{d H}^{*}$ & $\mathbf{d E}^{*}$ \\
\hline C_1 & -0.17 & -0.46 & 0.25 & 0.55 \\
C_3x & -0.36 & -0.78 & 0.33 & 0.92 \\
C_5x & -0.29 & -0.23 & 0.19 & 0.42 \\
\hline
\end{tabular}

Table 6. Change in color coordinates of the cotton sample treated with 3\% Al mordants after 1st, 3rd and 5th washing cycle (compared with C_3\%Al_0x).

\begin{tabular}{ccccc}
\hline Samples & $\mathbf{d L}^{*}$ & $\mathbf{d C}^{*}$ & $\mathbf{d H}^{*}$ & $\mathbf{d E}^{*}$ \\
\hline C_3\%Al_1x & -0.03 & 1.06 & 0.80 & 1.33 \\
C_3\%Al_3x & 0.09 & 1.19 & 0.75 & 1.41 \\
C_3\%Al_5x & 0.13 & 1.48 & 0.69 & 1.64 \\
\hline
\end{tabular}


Table 7. Change in color coordinates of the cotton sample treated with $5 \% \mathrm{Al}$ mordants after 1st, 3rd and 5th washing cycle (compared with C_5\%Al_0x).

\begin{tabular}{ccccc}
\hline Samples & $\mathrm{dL}^{*}$ & $\mathrm{dC}^{*}$ & $\mathrm{dH}^{*}$ & $\mathrm{dE}^{*}$ \\
\hline C_5\%Al_1x & 0.24 & 1.51 & 0.74 & 1.70 \\
C_5\%Al_3x & 0.32 & 1.55 & 0.79 & 1.77 \\
C_5\%Al_5x & 0.40 & 1.67 & 0.71 & 1.86 \\
\hline
\end{tabular}

Table 8. Change in color coordinates of cotton samples dyed with SJL aqueous extract without mordants after 1st, 3rd and 5th washing cycle (compared with C_1E_0\%Al_0x).

\begin{tabular}{ccccc}
\hline Samples & $\mathbf{d L}^{*}$ & $\mathbf{d C}^{*}$ & $\mathbf{d H}^{*}$ & $\mathbf{d E}^{*}$ \\
\hline C_1E_0\%Al_1x & 3.78 & -18.36 & -7.41 & 20.15 \\
C_1E_0\%Al_3x & 4.64 & -15.08 & -18.69 & 24.46 \\
C_1E_0\%Al_5x & 5.12 & -14.15 & -20.61 & 25.52 \\
\hline
\end{tabular}

Table 9. Change in color coordinates of cotton samples dyed with SJL aqueous extract with $3 \% \mathrm{Al}$ mordants after 1st, 3rd and 5th washing cycle (compared with C_1E_3\%Al_0x).

\begin{tabular}{ccccc}
\hline Samples & $\mathbf{d L}^{*}$ & $\mathbf{d C}^{*}$ & $\mathbf{d H}^{*}$ & $\mathbf{d E}^{*}$ \\
\hline C_1E_3\%Al_1x & 3.45 & -18.87 & -5.39 & 19.93 \\
C_1E_3\%Al_3x & 4.32 & -17.13 & -16.09 & 23.90 \\
C_1E_3\%Al_5x & 5.00 & -15.61 & -19.79 & 25.70 \\
\hline
\end{tabular}

Table 10. Change in color coordinates of cotton samples dyed with SJL aqueous extract with $5 \% \mathrm{Al}$ mordants after 1st, 3rd and 5th washing cycle (compared with C_1E_5\%Al_0x).

\begin{tabular}{ccccc}
\hline Samples & $\mathbf{d L}^{*}$ & $\mathbf{d C}^{*}$ & $\mathbf{d H}^{*}$ & $\mathbf{d E}^{*}$ \\
\hline C_1E_5\%Al_1x & 3.37 & -19.38 & -4.38 & 20.15 \\
C_1E_5\%Al_3x & 4.42 & -17.90 & -16.68 & 24.87 \\
C_1E_5\%Al_5x & 4.84 & -17.07 & -18.78 & 25.84 \\
\hline
\end{tabular}

The difference in the sensation of color after washing was presented by Delta $\mathrm{E}^{*}$ values. Table 5 shows there are no significant differences among washed and unwashed samples since Delta $E^{*}$ is lower than 2 which is an indicator that the differences are within the tolerance limits.

Tables 6 and 7 show that metal (Al) from alum mordant binds well and firmly to the cotton material, especially when applied in higher concentrations (5\%). Comparing only the best results from Tables 6 and 7 (samples after 1 washing cycle) with an untreated cotton sample from Table 5 (Delta $E^{*}=0.55$ ) it can be seen that Delta $E^{*}$ has increased and amounts 1.33 and 1.70 , respectively.

Table 8 shows high colorfastness to washing (after 1st washing cycle) of cotton dyed samples without pre-mordant (Delta $\left.E^{*}=20.15\right)$. Delta $E^{*}$ higher than 2 indicates that differences in coloration are visible with the naked eye and are outside the tolerance limits. A higher number of washing cycles influences Delta $E^{*}$ values indicating a greater color change of sample after 5 washing cycles (Delta $E^{*}=25.52$ ).

Results of pre-mordant and dyed cotton material are presented in Tables 9 and 10. It is noticeable that metal $\left(\mathrm{Al}^{3+}\right)$ from alum mordant does not make strong chemical bonds with dye since Delta $\mathrm{E}^{*}$ values increase regarding the higher concentration of alum and higher number of washing cycles, as well. This is also confirmed with differences in lightness and hue values, which directly affect Delta $E^{*}$. The difference in lightness value $\left(\mathrm{dL}^{*}\right)$ has the smallest influence on the total difference in coloration $\left(\mathrm{dE}^{*}\right)$. The $\mathrm{dL}^{*}$ values are under 5.00 while differences in hue $\left(\mathrm{dH}^{*}\right)$ are increasing with a higher number of washing cycles and are in the range of approx. 16.00 to 20.00 indicating a noticeable change in samples' color. 
Table 11. Visual assessment of colorfastness to washing.

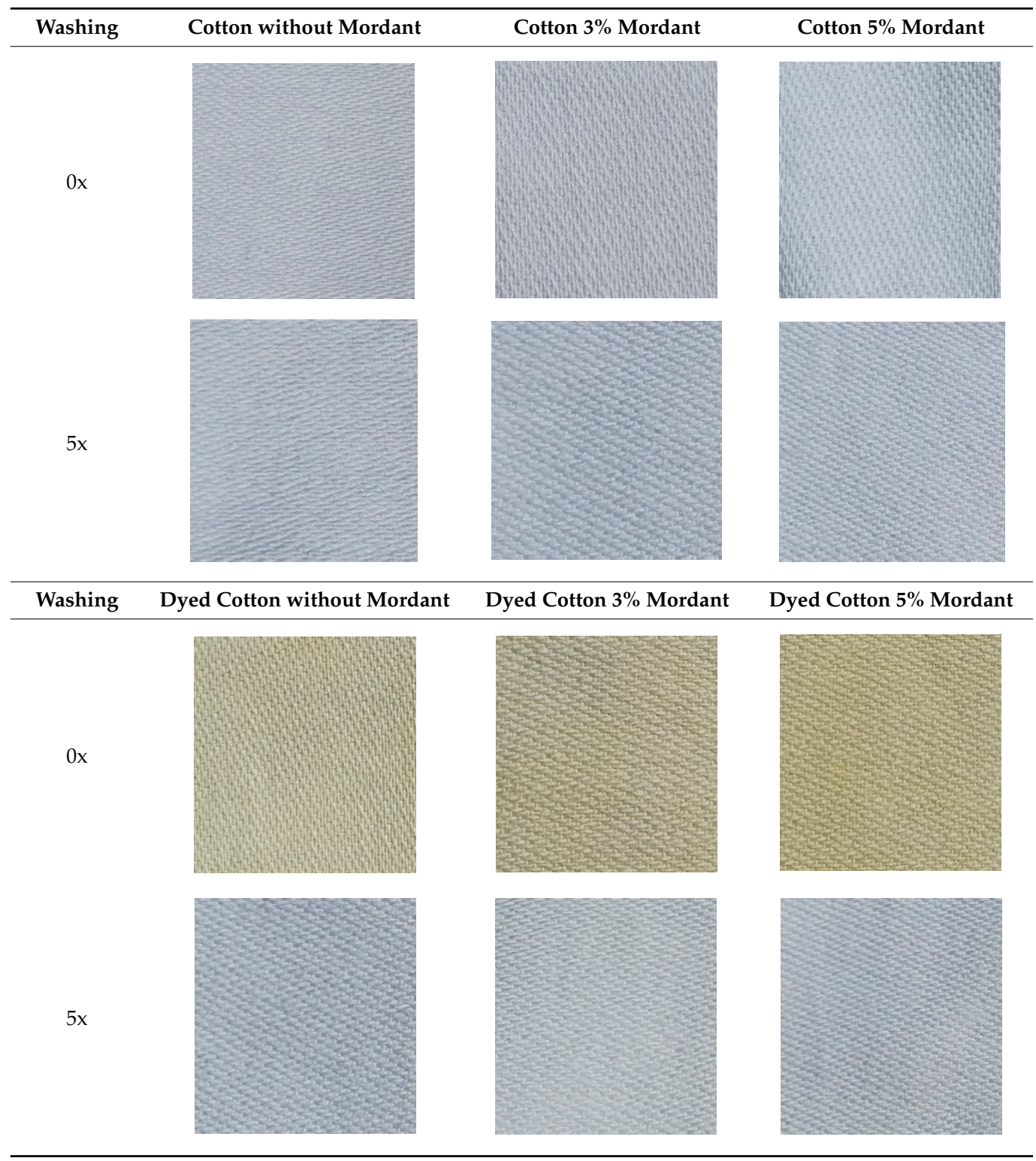

Table 12. Change in color coordinates of the wool sample without mordants after 1st, 3rd and 5th washing cycle (compared with W_0x).

\begin{tabular}{ccccc}
\hline Samples & $\mathrm{dL}^{*}$ & $\mathrm{dC}^{*}$ & $\mathrm{dH}^{*}$ & $\mathrm{dE}^{*}$ \\
\hline W_1x & -0.96 & 0.79 & -0.03 & 1.24 \\
W_3x & -1.51 & 2.02 & -0.38 & 2.55 \\
W_5x & -1.59 & 2.50 & -0.48 & 3.00 \\
\hline
\end{tabular}

Table 13. Change in color coordinates of wool sample treated with $3 \% \mathrm{Al}$ mordants after 1st, 3rd and 5th washing cycle (compared with W_3\%Al_0x).

\begin{tabular}{ccccc}
\hline Samples & $\mathbf{d L}^{*}$ & $\mathbf{d C}^{*}$ & $\mathbf{d H}^{*}$ & $\mathbf{d E}^{*}$ \\
\hline W_3\%Al_1x & 0.22 & 0.75 & 0.01 & 0.78 \\
W_3\%Al_3x & -1.09 & 2.45 & -0.40 & 2.71 \\
W_3\%Al_5x & -1.64 & 3.58 & -0.80 & 4.02 \\
\hline
\end{tabular}


Table 14. Change in color coordinates of wool sample treated with $5 \% \mathrm{Al}$ mordants after 1st, 3rd and 5th washing cycle (compared with W_5\%Al_0x).

\begin{tabular}{ccccc}
\hline Samples & $\mathrm{dL}^{*}$ & $\mathrm{dC}^{*}$ & $\mathrm{dH}^{*}$ & $\mathrm{dE}^{*}$ \\
\hline W_5\%Al_1x & -0.46 & 0.58 & 0.08 & 0.74 \\
W_5\%Al_3x & -1.47 & 1.69 & -0.04 & 2.24 \\
W_5\%Al_5x & -1.84 & 2.60 & -0.23 & 3.19 \\
\hline
\end{tabular}

Table 15. Change in color coordinates of wool sample dyed with SJL aqueous extract without mordants after 1st, 3rd and 5th washing cycle (compared with W_1E_0\%Al_0x).

\begin{tabular}{ccccc}
\hline Samples & $\mathbf{d L}^{*}$ & $\mathbf{d C}^{*}$ & $\mathbf{d H}^{*}$ & $\mathbf{d E}^{*}$ \\
\hline W_1E_0\%Al_1x & -1.03 & 1.60 & -1.46 & 2.39 \\
W_1E_0\%Al_3x & -0.35 & -0.90 & -1.52 & 1.80 \\
W_1E_0\%Al_5x & 0.56 & -3.22 & -1.55 & 3.61 \\
\hline
\end{tabular}

Table 16. Change in color coordinates of cotton samples dyed with SJL aqueous extract with $3 \% \mathrm{Al}$ mordants after 1st, 3rd and 5th washing cycle (compared with W_1E_3\%Al_0x).

\begin{tabular}{ccccc}
\hline Samples & $\mathbf{d L}^{*}$ & $\mathbf{d C}^{*}$ & $\mathbf{d H}^{*}$ & $\mathrm{dE}^{*}$ \\
\hline W_1E_3\%A1_1x & -1.58 & 7.14 & -1.31 & 7.43 \\
W_1E_3\%Al_3x & -0.62 & 4.71 & -0.98 & 4.85 \\
W_1E_3\%A1_5x & 0.65 & -0.27 & -0.51 & 0.87 \\
\hline
\end{tabular}

Table 17. Change in color coordinates of wool sample dyed with SJL aqueous extract with $5 \% \mathrm{Al}$ mordants after 1st, 3rd and 5th washing cycle (compared with W_1E_5\%Al_0x).

\begin{tabular}{ccccc}
\hline Samples & $\mathbf{d L}^{*}$ & $\mathbf{d C}^{*}$ & $\mathbf{d H}^{*}$ & $\mathbf{d E}^{*}$ \\
\hline W_1E_5\%A1_1x & -2.13 & 8.68 & -1.37 & 9.04 \\
W_1E_5\%Al_3x & -1.28 & 8.80 & -1.01 & 8.94 \\
W_1E_5\%Al_5x & -0.08 & 3.25 & -0.29 & 3.27 \\
\hline
\end{tabular}

Visual assessment of colorfastness to washing can be seen in Table 11. In the first part of Table 11, undyed cotton samples were presented and the effect of washing on its discoloration is almost negligible.

Dyed cotton samples were presented in the second part of Table 11. Discoloration of samples after the washing process is significant especially since the color change is quite noticeable after 5 washing cycles.

Table 12 shows that there are significant differences among washed samples after 3 and 5 washing cycles and unwashed samples. Delta $E^{*}$ is lower than 2 for wool untreated samples after 1st washing cycle (Delta $\mathrm{E}^{*}=1.24$ ) which is an indicator that the differences are within the tolerance limits.

Tables 13 and 14 show that metal (Al) from alum mordant binds well and firmly to the wool material, especially when applied in higher concentrations (5\%). Comparing only the best results from Tables 13 and 14 (samples after 1 washing cycle) with the untreated wool sample from Table 12 (Delta $E^{*}=1.24$ ) it can be seen that Delta $E^{*}$ has decreased by $100 \%$ and amounts 0.78 and 0.74 , respectively.

Table 15 shows better colorfastness to washing of wool dyed samples without premordant (Delta $E^{*}=2.39$ ) in comparison to the cotton sample treated under the same conditions. Delta $E^{*}$ higher than 2 indicates that differences in coloration are visible with the bare eye and are outside the tolerance limits.

Results of pre-mordant and dyed wool material are presented in Tables 16 and 17. It is interesting that wool samples treated with mordant show a decrease in Delta $\mathrm{E}^{*}$ values regarding a higher number of washing cycles. 
Table 18. Visual assessment of colorfastness to washing.

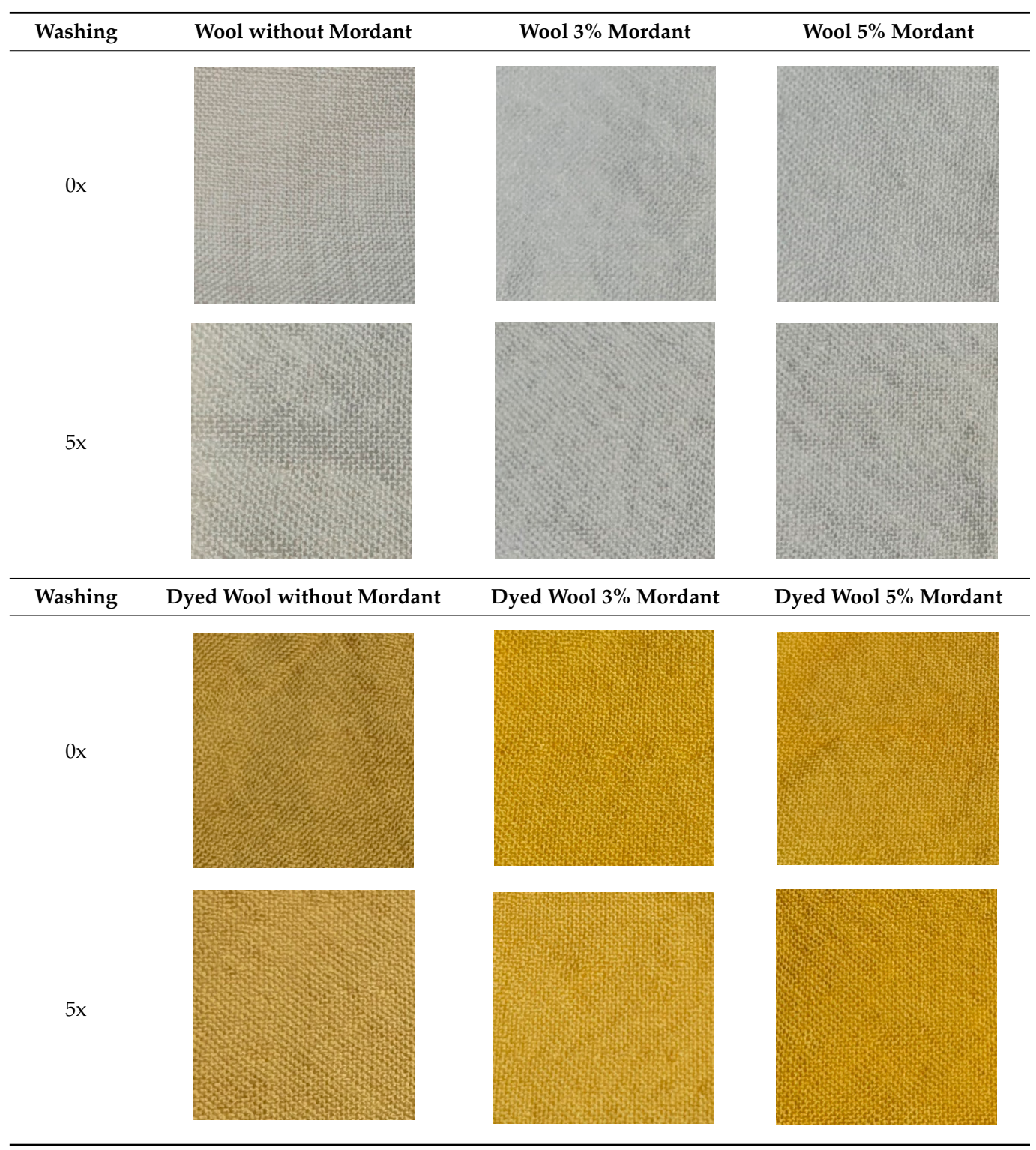

The best result is shown in Table 16 by the sample treated with $3 \%$ alum after 5 washing cycles (Delta $E^{*}=0.87$ ). These results confirm that metal (Al) from alum mordant make strong chemical bonds with wool substrate and dye since Delta $\mathrm{E}^{*}$ values decrease in comparison to Delta $E^{*}$ values of the cotton samples treated in the same way. These results correlate well with the research of Haji, A. [47] and Pour, R.A. [48] who have shown that optimization of metal mordants concentrations and usage of lower concentration can improve colorfastness to washing. Although cotton samples did not show significant differences among various mordant concentrations, wool samples show that the concentration of mordant has a significant effect on the obtained results and on the dyeing effects as well as colorfastness properties. Lightness values are dependent on both mordant concentration and number of washing cycles [49]. Higher mordant concentration influences lower lightness value while a higher number of washing cycles shows a slightly higher lightness value. Considering only wool samples pre-mordant with $3 \%$ alum and dyed, its $\mathrm{L}^{*}$ value is in the range from 70.91 for unwashed samples to 71.56 for samples after 5 washing cycles (Table 4). All the dyed samples show color coordinates in a red-yellow zone. The $\mathrm{a}^{*}$ is increasing, while $b^{*}$ is decreasing with higher numbers of washing cycles, except for the sample treated with $5 \%$ alum where is visible a minor increase in $b^{*}$ value-from 51.02 
for the unwashed sample to 54.19 for sample after 5 washing cycles. Hue angle shows the highest values for unwashed samples and for the sample treated with $3 \%$ alum.

Visual assessment of colorfastness to washing for wool fabrics was performed as well and presented in Table 18. The effect of the washing process on its color change is visible within $L^{*}$ value which shows lighter shades with regard to higher mordant concentration ( $\mathrm{L}^{*}$ from 90.45 for unmordant to 91.24 for the sample treated with $5 \%$ alum) and darker shades with regard to a higher number of washing cycles ( $\mathrm{L}^{*}$ from 90.45 for unwashed wool without a mordant sample to 88.86 for the same sample after 5 washing cycles).

Discoloration of woolen samples after the washing process is significantly lower than was the case with cotton samples. According to Li, Y.V. et al. if the natural dye is bonded with mordant forming a stable dye-metal complex then the water solubility of the dye is lower and the color is less likely to bleed out on washing process [50]. Lightness value was decreasing while increasing mordant concentration ( $\mathrm{L}^{*}$ from 71.70 for unmordant sample to 69.96 for the sample treated with $5 \%$ alum) providing darker shades of wool fabrics which are in contrast to increasing the $L^{*}$ value when increasing the number of washing cycles ( $\mathrm{L}^{*}$ from 70.91 for unwashed and with 3\% alum pre-mordanted sample to 71.56 for the same sample after 5 washing cycles) providing a little bit lighter shades.

\subsubsection{FT-IR Spectra of Dye Wool Fabrics}

FTIR spectra of reference (unmordant, undyed and unwashed) and dyed wool fabrics are presented in Figure 8. Spectra of all samples show absorption peaks at $3276 \mathrm{~cm}^{-1}$ assigned to the NH stretching vibrations, $1631 \mathrm{~cm}^{-1}$ assigned to amide-I ( $\mathrm{C}=\mathrm{O}$ stretching), $1515 \mathrm{~cm}^{-1}$ assigned to amide-II (NH bending and CN stretching) and $1075 \mathrm{~cm}^{-1}$ assigned to CN stretching and NHG bending of amide-III [51]. The peak at $1391 \mathrm{~cm}^{-1}$ is assigned to the amino acid (COO-) functional group. A peak at $1233 \mathrm{~cm}^{-1}$ is assigned to $\mathrm{CH}_{2}$ and $\mathrm{CH}_{3}$ bending. Dyed samples showed a little bit lower intensity of peaks characteristic for amide-I and amide-II compared to untreated wool indicating the involvement of amine functional groups within the wool, alum and dye molecules [45]. Untreated wool shows a peak at $1515 \mathrm{~cm}^{-1}$ (peak characteristic for amide-II) which closely corresponds to the peak at $1513 \mathrm{~cm}^{-1}$ of investigated dye solution. An increase of intensity of a very weak band at $1125 \mathrm{~cm}^{-1}$ which is assigned to amide-II due to CN stretch is visible in the pre-mordant and dyed wool spectra indicating the effect of alum mordant. Peak visible in an untreated wool sample at $506 \mathrm{~cm}^{-1}$ is assigned to the S-S bond. In pre-mordant and dyed samples this peak hasn't been detected since the area from $500-600 \mathrm{~cm}^{-1}$ showed several peaks of minor intensity characteristic for sulfate absorption and Al-O stretching vibration from alum mordant (539 and $\left.565 \mathrm{~cm}^{-1}\right)[48,52,53]$.

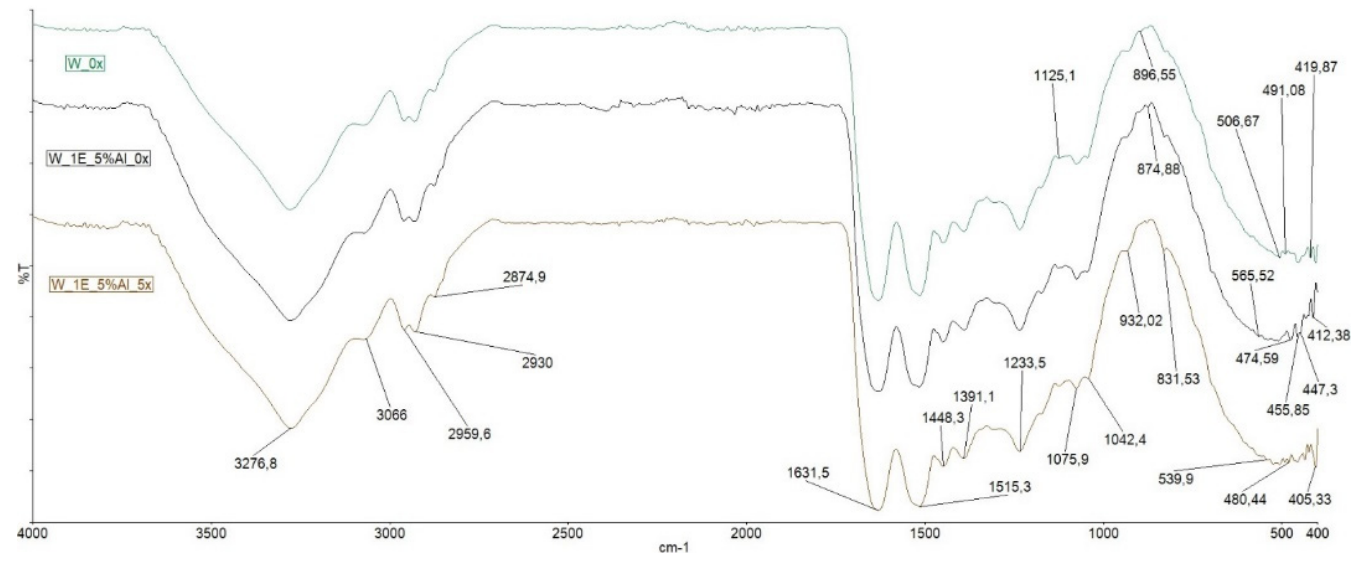

Figure 8. FTIR spectra of wool fabrics, where W_0x is reference fabric, W_1E_5\%Al_0x is pre-mordant with 5\% alum, dyed and unwashed wool fabric and W_1E_5\%Al_5x is the same sample as previous but after 5 washing cycles. 


\section{Conclusions}

The paper proved that the extracted dye from Spartium junceum L. is an acidic dye (mordant dye) that is successfully used for the treatment of protein fibers. Cellulose fibers can also be dyed with acidic dye, but optimization of conditions is required. Dyed wool samples show higher intensity in coloration than cotton samples. Wool samples that are dyed and pre-mordant with $5 \%$ alum show the lowest lightness value $\left(\mathrm{L}^{*}=69.96\right)$ and highest chroma $\left(C^{*}=51.64\right)$ regarding the other dyed samples. Discoloration of wool samples after the washing process is significantly lower than was the case with cotton samples. The best results were achieved with wool samples treated with $3 \%$ alum where Delta $E^{*}$ after 5 washing cycles was 0.87 and within the tolerance limits. A further conclusion is in the possibility to reduce the concentration of mordant to $3 \%$ to obtain satisfactory results regarding colorfastness. Otherwise, approx. $15 \%$ of mordant is added, and this significant reduction favors potentially increased negative environmental impact. This research shows wide practical application due to the aspects of circular economy, textile care and environmental friendliness. According to the zero waste model, this research is focused on the total utilization of the SJL plant. The majority of the SJL plant usage has been successfully processed in our previous research. The least used part of the SJL plant is found out to be a valuable source of raw material for natural dye production. Such dyes show better affection to protein fibers and consequently better color fastness, which enables its application for dyeing the textile materials suitable for multi-cycle washing. Positive results gained after reduction of alum mordant concentration influence usage of SJL natural dye in a more environmentally friendly manner and allow its response to the stringent requests of various EU regulations. Nonetheless, future research will go in the direction of replacing a synthetic mordant with a more environmentally friendly mordant. Furthermore, these findings lead us to the interdisciplinary approach and wider research on the usage of energy crop cultures which are investigated within the BIOCOMPOSITES project, such as Miscanthus $x$ giganteus, Sida hermaphrodita or Arundo donax, as a valuable resource for dyes extracted from their leaves, while at the same time facilitates their eventual application in practice.

Author Contributions: Conceptualization, Z.K. and A.S.; methodology, Z.K. and A.S.; software, Z.K.; validation, Z.K., A.S.; formal analysis, Z.K.; investigation, Z.K.; resources, Z.K.; data curation, Z.K.; writing—original draft preparation, Z.K.; writing—review and editing, A.S., A.M. and S.B.; visualization, Z.K.; supervision, A.S. and S.B; project leader, S.B.; All authors have read and agreed to the published version of the manuscript.

Funding: The research was funded by the European Regional Development Fund within K.K.01.1.1.04.0091 project "Design of Advanced Biocomposites from Renewable Energy Sources" (BIOCOMPOSITES).

Institutional Review Board Statement: Not applicable.

Informed Consent Statement: Not applicable.

Data Availability Statement: Data available in a publicly accessible repository.

Acknowledgments: The research was performed on equipment purchased by K.K.01.1.1.02.0024 project "Modernization of Textile Science Research Centre Infrastructure" (MI-TSRC).

Conflicts of Interest: The authors declare no conflict of interest.

\section{References}

1. Bischof, S.; Kovačević, Z. From Weed to Fabric; University of Zagreb Faculty of Textile Technology: Zagreb, Croatia, 2013; pp. 1-120.

2. Gavilan, R.G.; Sanchez-Mata, D.; Gaudencio, M.; Gutierrez-Giron, A.; Vilches, B. Impact of the non-indigenous shrub species Spartium junceum (Fabaceae) on native vegetation in central Spain. J. Plant. Ecol. 2016, 9, 132-143. [CrossRef]

3. Sanhueza, C.; Zalba, S.M. Experimental control of Spanish broom (Spartium junceum) invading natural grasslands. Manag. Biol. Invasions 2012, 3, 97-104. [CrossRef]

4. Gudelj Velaga, A.; Bilandžija, N.; Grubor, M.; Kovačević, Z.; Krička, T. Energy utilisation of biofibre production residues-Circular economy approach. In Proceedings of the 48th Symposium "Actual Tasks on Agricultural Engineering”, Online Symposium, 2-4 March 2021; pp. 463-472. 
5. Duman, R.; Dogan, H.H.; Karakis, H. Antiviral activity of Spartium junceum against herpes simplex virus type 1: An in-vitro study. Int. J. Pharm. Sci. Res. 2019, 10, 3274-3282. [CrossRef]

6. Kovačević, Z.; Sutlović, S.; Bischof, S. Spartium Junceum L. As Natural Dyestuff for Wool Dyeing. In Proceedings of the 7th International Textile, Clothing \& Design Conference-Magic World of Textiles, Dubrovnik, Croatia, 5-8 October 2014; pp. 220-225.

7. Karaboyaci, M.; Ugur, S.S. Ecological wool dyeing with pulps of lavender, broom, and red wine. J. Text. Inst. 2014, 105, 821-827. [CrossRef]

8. Regulation (EC) No 1907/2006 of the European Parliament and of the Council of 18 December 2006 Concerning the Registration, Evaluation, Authorisation and Restriction of Chemicals (REACH). Available online: https:/ / eur-lex.europa.eu/LexUriServ/ LexUriServ.do?uri=OJ:L:2007:136:0003:0280:EN:PDF (accessed on 15 July 2021).

9. Regulation (EC) No 66/2010 of the European Parliament and of the Council of 25 November 2009 on the EU Ecolabel. Available online: https: / / eur-lex.europa.eu/LexUriServ/LexUriServ.do?uri=OJ:L:2010:027:0001:0019:en:PDF (accessed on 15 July 2021).

10. Kasiri, M.B.; Safapour, S. Exploring and Exploiting Plants Extracts as the Natural Dyes/Antimicrobials in Textiles Processing. Prog. Color. Colorants Coat. 2015, 8, 87-114.

11. Repon, M.R.; Islam, M.T.; Al Mamun, M.A. Ecological risk assessment and health safety speculation during color fastness properties enhancement of natural dyed cotton through metallic mordants. Fash. Text. 2017, 4, 1-17. [CrossRef]

12. Schweppe, H. Handbuch der Naturfarbstoffe: Vorkommen, Verwndung, Nachweis, 1st ed.; Ecomed: Landsberg/Lech, Germany, 1992; pp. 1-799.

13. Kumar Gupta, V. Fundamentals of Natural Dyes and Its Application on Textile Substrates. In Chemistry and Technology of Natural and Synthetic Dyes and Pigments; Samanta, A.K., Awwad, N.S., Algarni, H.M., Eds.; IntechOpen Limited: London, UK, 2019; Chapter 1; pp. 1-32. [CrossRef]

14. Chakraborty, J.N. Dyeing with natural dyes. In Fundamentals and Practices in Colouration of Textiles, 2nd ed.; Chakraborty, J.N., Ed.; Woodhead Publishing India: New Delhi, India, 2014; Chapter 20; pp. 233-261. [CrossRef]

15. Narbona, E.; del Valle, J.C.; Whittall, J.B. Painting the green canvas: How pigments produce flower colours. Biochemist 2021, 43, 6-12. [CrossRef]

16. Deveoglu, O.; Karadag, R. A review on the Flavonoids-A Dye Source. Int. J. Adv. Eng. Pure Sci. 2019, 3, 188-200. [CrossRef]

17. Tang, X.; Zhong, W.; Zhuang, D.; Li, C.; Liu, Y. Study on Microwave-Assisted Extraction of the Yellow Pigment from Orange Peel. Appl. Mech. Mater. 2013, 295, 287-292. [CrossRef]

18. Wang, H.; Shi, L.; Yang, X.; Hong, R.; Li, L. Ultrasonic-Assisted Extraction of Natural Yellow Pigment from Physalis pubescens L. and Its Antioxidant Activities. J. Chem. 2018, 2018, 1-7. [CrossRef]

19. Baldino, L.; Scognamiglio, M.; Reverchon, E. Supercritical fluid technologies applied to the extraction of compounds of industrial interest from Cannabis sativa L. and to their pharmaceutical formulations: A review. J. Supercrit. Fluids. 2020, 165, 104960. [CrossRef]

20. Bočak, A.M.; Brunšek, R.; Tarbuk, A.; Sutlović, A. Linen fabric dyed with flavonoid compounds extracted from waste onion skin. In Proceedings of the 13th International Scientific-Professional Symposium Textile Science and Economy, Chinese-Croatian Forum, Zagreb, Croatia, 18 September 2020; pp. 104-109.

21. Patel, B.H. Natural dyes. In Handbook of Textile and Industrial Dyeing, 2nd ed.; Clark, M., Ed.; Woodhead Publishing: Cambridge, UK, 2011; Chapter 11; pp. 395-424. [CrossRef]

22. Coelho Pinheiro, M.N.; Castro, L.M.; Veloso, A.C.; Moreira, M.J.; Lagoa, B.; Ferreira, D. Biomass residues as a source of natural dyes for textile industries: The case study of cork powder. In Proceedings of the 27th European Biomass Conference and Exhibition, Lisbon, Portugal, 27-30 May 2019; pp. 1450-1455.

23. Dutta, P.; Mahjebin, S.; Abu Sufian, M.; Rabbi, M.d.R.; Chowdhury, S.; Imran, I.H. Impacts of natural and synthetic mordants on cotton knit fabric dyed with natural dye from onion skin in perspective of eco-friendly textile process. Mater. Today Proc. 2021, 1-8. [CrossRef]

24. Mitra, A. Natural Dye Mordants and their Health Hazards. J. Text. Assoc. 2015, 75, 405-410.

25. Ezatollah, M.; Bijan, M. Alum Mineral and the Importance for Textile Dyeing. Curr. Trends Fash. Technol. Text. Eng. 2018, 3, 1-3. [CrossRef]

26. Sutlović, A.; Brlek, I.; Ljubić, V.; Glogar, M.I. Optimization of Dyeing Process of Cotton Fabric with Cochineal Dye. Fibers Polym. 2020, 21, 555-563. [CrossRef]

27. Chakraborty, J.N. Dyeing with acid dye. In Fundamentals and Practices in Colouration of Textiles, 1st ed.; Chakraborty, J.N., Ed.; Woodhead Publishing India: New Delhi, India, 2010; Chapter 15; pp. 166-174. [CrossRef]

28. Hofenk de Graaff, J.H. The Colourful Past: Origins, Chemistry and Identification of Natural Dyestuffs, 1st ed.; Abegg-Stiftung: Riggisberg, Switzerland; Archetype Publications Ltd.: London, UK, 2004; pp. 1-396.

29. Chungkrang, L.; Bhuyan, S.; Phukan, A.R. Natural Dyes: Extraction and Applications. Int. J. Curr. Microbiol. Appl. Sci. 2021, 10, 1669-1677. [CrossRef]

30. Kechi, A.; Chavan, R.B.; Moeckel, R. Dye Yield, Color Strength and Dyeing Properties of Natural Dyes Extracted from Ethiopian Dye Plants. Text. Light. Ind. Sci. Technol. 2013, 2, 137-145.

31. Vankar, P.S.; Shukla, D. Spectrum of colors from reseda luteola and other natural yellow dyes. J. Text. Eng. Fash. Technol. 2018, 4, 105-118. [CrossRef] 
32. Anouar, E.H.; Gierschner, J.; Duroux, J.-L.; Trouillas, P. UV/Visible spectra of natural polyphenols: A time-dependent density functional theory study. Food Chem. 2012, 131, 79-89. [CrossRef]

33. Amat, A.; Clementi, C.; de Angelis, F.; Sgamellotti, A.; Fantacci, S. Absorption and Emission of the Apigenin and Luteolin Flavonoids: A TDDFT Investigation. J. Phys. Chem. A 2009, 113, 15118-15126. [CrossRef]

34. Nickavar, B.; Amin, G.; Mehregan, N. Quercetin, a Major Flavonol Aglycon from Tanacetum balsamita L. Iran. J. Pharm. Res. 2003, 2, 249-250. [CrossRef]

35. Maitera, O.N.; Louis, H.; Barminas, J.T.; Akakuru, O.U.; Boro, G. Synthesis and Characterization of Some Metal Complexes Using Herbal Flavonoids. Nat. Prod. Chem. Res. 2018, 6, 1-14. [CrossRef]

36. Baranović, G.; Šegota, S. Infrared spectroscopy of flavones and flavonols. Reexamination of the hydroxyl and carbonyl vibrations in relation to the interactions of flavonoids with membrane lipids. Spectrochim. Acta A Mol. Biomol. Spectrosc. 2018, 192, 473-486. [CrossRef]

37. Oliveira, R.N.; Mancini, M.C.; Salles de Oliveira, F.C.; Passos, T.M.; Quilty, B.; da Silva Moreira Thire, R.M.; McGuinness, G.B. FTIR analysis and quantification of phenols and flavonoids of five commercially available plants extracts used in wound healing. Materia 2016, 21, 767-779. [CrossRef]

38. Abbas, O.; Compere, G.; Larondelle, Y.; Pompeu, D.; Rogez, H.; Baeten, V. Phenolic compound explorer: A mid-infrared spectroscopy database. Vib. Spectrosc. 2017, 92, 111-118. [CrossRef]

39. Alighiri, D.; Edie, S.S.; Drastisianti, A.; Khasanah, U.; Tanti, K.A.; Maghfiroh, R.Z.; Kirana, K.G.; Choirunnisa, F. Identification of flavonoid compounds and total flavonoid content from biowaste of local durian shell (Durio zibethinus). J. Phys. Conf. Ser. 2020, 1567, 042084. [CrossRef]

40. Heneczkowski, M.; Kopacz, M.; Nowak, D.; Kuzniar, A. Infrared Spectrum Analysis of Some Flavonoids. Acta Pol. Pharm. 2001, 58, 415-420. [PubMed]

41. Glogar, M.I.; Parac-Osterman, Đ.; Grundler, D.; Rolich, T. Research of influences of surface structure of coloured textiles: Applying fuzzy logic. Color. Technol. 2011, 127, 396-403. [CrossRef]

42. Zhang, Y.; Zhou, Q.; Rather, L.J.; Li, Q. Agricultural waste of Eriobotrya japonica L. (Loquat) seeds and flora leaves as source of natural dye and bio-mordant for coloration and bio-functional finishing of wool textile. Ind. Crop. Prod. 2021, 169, 113633. [CrossRef]

43. Singh, A.; Sheikh, J. Cleaner functional dyeing of wool using Kigelia Africana natural dye and Terminalia chebula bio-mordant. Sustain. Chem. Pharm. 2020, 17, 1-6. [CrossRef]

44. Adeel, S.; Habib, N.; Arif, S.; ur Rehman, F.; Azeem, M.; Batool, F.; Amin, N. Microwave-assisted eco dyeing of bio-mordanted silk fabric using cinnamon bark (Cinnamomum Verum) based yellow natural dye. Sustain. Chem. Pharm. 2020, 17, 100306. [CrossRef]

45. Singh, G.; Mathur, P.; Singh, N.; Sheikh, J. Functionalization of wool fabric using kapok flower and bio-mordant. Sustain. Chem. Pharm. 2019, 14, 100184. [CrossRef]

46. Haji, A.; Mehrizi, M.K.; Sharifzadeh, J. Dyeing of Wool with Aqueous Extract of Cotton Pods Improved by Plasma Treatment and Chitosan: Optimization Using Response Surface Methodology. Fibers Polym. 2016, 17, 1480-1488. [CrossRef]

47. Haji, A. Dyeing of Cotton Fabric with Natural Dyes Improved by Mordants and Plasma Treatment. Prog. Color. Colorants Coat. 2019, 12, 191-201.

48. Pour, R.A.; He, J. Surface Functionalization of Wool via Microbial-Transglutaminase as Bio-Mordant to Improve Dyeability with Madder in the Presence of Alum. Coatings 2020, 10, 78. [CrossRef]

49. Loum, J.; Byamukama, R.; Wanyama, P. Application of natural dyes from selected indigenous plants on cotton and silk fabrics. J. Text. Eng. Fash. Technol. 2021, 7, 71-77. [CrossRef]

50. Li, Y.V.; Malensek, N.; Sarkar, A.K.; Xiang, C. Colorfastness Properties of Persimmon Dye on Cotton and Wool Fabrics. Cloth. Text. Res. J. 2016, 34, 223-234. [CrossRef]

51. Malensek, N. Colorfastness Properties of Persimmon Dye on Cotton and Wool Substrates. Master's Thesis, Colorado State University, Fort Collins, CO, USA, April 2014.

52. Bonacini, I. Development of New Analytical Procedures Aimed at the Characterization of Artistic Samples. Ph.D. Thesis, University of Bologna, Ravenna, Italy, June 2015.

53. Lee, J.; Kang, M.H.; Lee, K.-B.; Lee, Y. Characterization of Natural Dyes and Traditional Korean Silk Fabric by Surface Analytical Technique. Materials 2013, 6, 2007-2025. [CrossRef] [PubMed] 